\title{
CORRECTION
}

\section{Correction to: The minimally invasive flexor carpi radialis approach: a new perspective for distal radius fractures}

\author{
Yuka Igeta $^{1,2} \cdot$ Paul Vernet $^{1} \cdot$ Sybille Facca ${ }^{1} \cdot$ Ismaël Naroura $^{1}$. Juan José Hidalgo Diaz ${ }^{1}$ Philippe A. Liverneaux ${ }^{1}$
}

Published online: 3 March 2018

(c) Springer-Verlag France SAS, part of Springer Nature 2018

Correction to: European Journal of Orthopaedic Surgery \& Traumatology https://doi.org/10.1007/s00590-018-2124-z

With regards to Juan José Hidalgo Diaz, fifth author. The author's name is incorrectly listed on Pub-Med. The first and last name has been mixed up.

Correct first name is: JJ (on PubMed: JJH.).

Correct last name is: Hidalgo Diaz (on PubMed: Diaz).

On SpringerLink the name is listed correctly, but on PubMed he is listed as Diaz JJH.

Philippe A. Liverneaux

philippe.liverneaux@chru-strasbourg.fr

1 Icube CNRS 7357, Department of Hand Surgery, SOS

Main, CCOM, University Hospital of Strasbourg,

FMTS, University of Strasbourg, 10 Avenue Baumann,

67400 Illkirch, France

2 Department of Orthopedic Surgery, Juntendo University, Tokyo, Japan 